\title{
Pengujian Empiris Pengaruh Ketidakpastian Kebijakan Ekonomi Amerika Serikat Terhadap Dinamika Perekonomian Indonesia
}

\author{
(Empirical Testing of the Effects of United States Economic Policy Uncertainty on \\ Indonesian Economic)
}

\author{
Suwito*, Siswoyo Hari Santosa, Duwi Yunitasari \\ Jurusan Ilmu Ekonomi dan Studi Pembangunan, Fakultas Ekonomi dan Bisnis, Universitas Jember (UNEJ) \\ Jln. Kalimantan 37, Jember 68121 \\ E-mail: ito.iesp@gmail.com
}

\begin{abstract}
Abstrak
Keadaan perekonomian global yang tidak menentu merupakan salah satu fenomena yang terjadi pada saat ini. Kebijakan perekonomian yang tidak menentu pada negara maju berdampak pada perekonomian di negara berkembang. Penelitian ini menganalisis pengaruh ketidakpastian kebijakan ekonomi Amerika Serikat terhadap dinamika perekonomian Indonesia. Estimasi menggunakan metode vector autoregression (VAR) digunakan untuk mengetahui hubungan antar variabel. Kemudian data yang digunakan dalam penelitian ini mulai dari tahun 1998Q1-2016Q4. Hasil estimasi menunjukkan bahwa dinamika ketidakpastian kebijakan ekonomi Amerika serikat berperngaruh signifikan terhadap perekonomian Indonesia. Variabel EPU, nilai tukar US, dan berpengaruh signifikan terhadap pertumbuhan ekonomi Indonesia. Hasil ini dibuktikan dengan IRF yang mengindikasikan respon dari gejolak EPU yang direspon oleh variable GDP di Indonesia. Kondisi tersebut menunjukkan bahwa ketidakpastiaan kebijakan ekonomi Amerika Serikat berperngaruh terhadap kinerja perekonomian Indonesia.
\end{abstract}

Kata Kunci: EPU, Makroekonomi, Indonesia, Amerika Serikat, VAR.

\begin{abstract}
The global economic uncertainy situation is one of the phenomena that occurs at this time. Erratic economic policies in developed countries have an impact on the economy in developing countries. This study analyzes the influence of uncertainty in US economic policy on the dynamics of the Indonesian economy. Estimates using the vector autoregression method are used to determine the relationship between variables. Then the data used in this study began in 1998Q1-2016Q4. The estimation results show that the dynamics of uncertainty in US economic policies have a significant effect on the Indonesian economy. EPU variables, US exchange rates, and have a significant effect on Indonesia's economic growth. This result is proven by the $I R F$ which indicates the response from the EPU fluctuation which was responded to by the GDP variable in Indonesia. These conditions indicate that the uncertainty of the economic policies of the United States affects the performance of the Indonesian economy.
\end{abstract}

Keywords: EPU, Macroeconomics, Indonesia, United States, VAR.

\section{Pendahuluan}

Krisis keuangan tahun 2008 yang melanda sebagian besar perekonomian dunia telah memberikan pemikiran tentang dampak ketidakpastian pada kondisi makroekonomi. Kondisi tersebut kemudian didukung dengan kebijakan ekonomi yang tidak menentu mengikuti keadaan sosial politik yang ada. Indonesia sebagai negara berkembang yang memiliki keterbukaan ekonomi yang sangat besar juga tidak luput dari dampak ketidakpastian pada kondisi ekonomi global. Konsep dari dampak yang ditimbulkan oleh perubahan ekonomi global yang direspon oleh ekonomi domestik disebut sebagai dampak spillover Mwase et al. (2016); Samake \& Yang (2014). Efek yang ditimbulkan dari gejolak perekonomian luar negeri adalah melalui jalur keuangan dan perdagangan Warjiyo (2013). Hal ini semakin memberikan gambaran bahwa resiko eksternal yang ditimbulkan dari gejolak perekonomian luar negeri dapat terjadi pada perekonomian Indonesia.

Guncangan perekonomian global secara instan dapat di transmisikan melalui jalur keuangan, dimana jalur ini diyakini lebih rentan dari pada jalur perdagangan. Jalur keuangan dalam hal ini dapat dicontohkan melalui penurunan harga saham dunia dan merosotnya keuntungan yang dialami oleh perusahaan pada negara maju, yang secara langsung akan mengakibatkan penurunan liquiditas di pasar keuangan dunia. Terjadinya pengetatan liquiditas dan adanya ketidakpastian perekonomian negara maju, maka akan menyebabkan penurunan jumlah investasi Warjiyo (2013). Penurunan jumlah investasi tersebut dapat diartikan terjadinya arus capital outflow di negera berkembang oleh investor global, yang pada akhirnya memberikan tekanan pada depresiasi nilai tukar negara berkembang. Pada arah yang sama, capital outflow negara berkembang seperti Indonesia juga dapat disebabkan oleh membaiknya perekonomian negara maju, yang akhirnya mendorong melakukan kebijakan tapering off. Studi Dahlhaus \& Vasishtha (2014) menyatakan bahwa isu tapering off dari kebijakan Bank Sentral Amerika Serikat memberikan respon negatif terhadap kondisi negara berkembang.

Munculnya fenomena ketidakpastian global merupakan dampak dari kebijakan ekonomi yang dinamis yang

\footnotetext{
* Corresponding author
} 
dilakukan oleh negara-negara besar. Kondisi tersebut memberikan dampak terhadap gejolak perekonomian negara emerging market yang mayoritas memiliki perekonomian terbuka dan memiliki hubungan kegiatan perekonomian dengan negara besar tersebut. Beberapa resiko yang akan dihadapi oleh negara-negara kecil sebagai akibat ketidakpastian global adalah pelemahan kinerja perekonomian sehingga hal yang paling parah dapat terjadi adalah terjadinya krisis ekonomi.

Penelitian ini meneliti tentang ketidakpastian kebijakan ekonomi US dengan memeriksa dampak guncangan kebijakan ekonomi asing pada dinamika perekonomian Indonesia. Ketidakpastian kebijakan ekonomi bisa memiliki implikasi penting bagi ekonomi Indonesia. Sementara itu, sifat perekonomian Indonesia yang terbuka mengakibatkan ekonomi Indonesia sangat rentan terhadap guncangan eksternal, termasuk ketidakpastian kebijakan ekonomi yang berasal dari negara lain. Penelitian ini terkait erat dengan Wang (2007) yang sama-sama meneliti tentang dampak yang diakibatkan oleh ketidakpastian kondisi perekonomian US pada perekonomian domestik.

\section{Metode}

Penelitian ini menggunakan data sekunder berupa datatime series (runtut waktu) yaitu data dengan rentang penelitian antara tahun 1998Q1-2017Q4 di Negara Indonesia. Untuk menganalisis hubungan variabel domestik dalam merespon gejolak menggunakana data variabel domestik dalam negeri yaitu GDP. Penelitian ini mengadopsi indikator ketidakpastian kebijakan ekonomi yang dikembangkan oleh Bernal et al. (2016). Indeks ketidakpastian kebijakan ekonomi secara keseluruhan untuk AS terdiri dari tiga komponen: indeks berdasarkan cakupan surat kabar, ukuran dari ketentuan pajak, dan sebuah indikator dari ketidaksepakatan pemikir ekonomi.

Penelitian Ini mengadopsi model yang dibangun oleh Baker et al. (2016) dan Cheng (2017) dengan spesifikasi model penelitian sebagai berikut.

$$
G D P=f\left(E P U_{U S}, G D P_{U S}, T B S T_{U S}, C P I_{U S}, E X_{I D}\right)
$$

Dimana variabel domestik digunakan dalam penelitian ini untuk melihat merespon gejolak dari ketidakpastian kebijakan ekonomi luar negeri, penelitian ini menggunakana data variabel domestik dalam negeri yaitu GDP. Kemudian penelitian ini menggunakan variabel luar negeri yaitu yaitu Economic Volatility Index US (EPU_US), GDP US ( GDP_US), dan three month T-bill rate US (TBST_US), CPI US merupakan inflasi US, dan EX ID ekspor Indonesia. Kemudian dimasukan dalam model VAR dituliskan sebagai berikut:

$$
B(L) y_{t}=d+e_{t}
$$

Dimana y_t merupakan vector dari variabel endogen, $d$ adalah vector dari variabel yang dianggap konstan, kemudian e $t$ adalah bentuk dari reduksi atau error term. Dari model VAR tersebut kemudian dimasukan varibel domestik (GDP, inflasi, rasio perdagangan, dan nilai tukar) yang dipengaruhi oleh variabel luar negeri yaitu Economic Volatility Index US (EPU_US), GDP US ( GDP_US), dan three month T-bill rate US (TBST_US), dan CPI_US inflasi US.

\section{Hasil dan Pembahasan}

\section{Hasil Penelitian}

\section{Uji Stasioneritas Data}

Hasil uji stasioneritas data bertujuan untuk melihat kestasioneran data pada amsing-masing variabel yang digunakan dalam penelitian. Hasil uji stasioneritas data untuk pengujian empiris pengaruh ketidakpastian kebijakan ekonomi Amerika serikat terhadap dinamika perekonomian Indonesia dipaparkan dalam Tabel 4.1.

Tabel 4.1 Uji Stasioneritas

\begin{tabular}{cc}
\hline Variabel & Stasioneritas \\
\hline GDP_IND & $0,0000^{* *}$ \\
GDP_US & $0,0359^{*}$ \\
EPU_US & $0,0038^{*}$ \\
Interest Rate_US & $0,0017^{*}$ \\
Export_IND & $0,0000^{* *}$ \\
\hline
\end{tabular}

Sumber: Lampiran B

Pada variabel GDP_IND sebagai proksi perekonomian Indonesia, data stasioner pada tingkat first different dengan nilai probabilitas sebesar 0,0000 . Sementara pada variabel GDP_US sebagai proksi perekonomian Amerika Serikat, EPU_US sebagai proksi ketidakpastian perekonomian Ameri Serikat dan Interest Rate_US sebagai proksi suku bunga 3 bulanan Amerika Serikat stasioner pada tingkat level. Nilai probabilitas pada masing-masing variabel tersebut lebih kecil dari nilai alpha (5\%) yakni 0,0359; 0,0038 dan 0,0017 . Selanjutnya, pada variabel Export_IND sebagai proksi ekspor untuk Indonesia yang mencerminkan kinerja perdagangan, menunjukkan nilai stasioneritas pada tingkat first different dengan nilai probabilitas sebesar 0,0000 lebih kecil dari dari nilai alpha (5\%). Hasil ini dapat disimpulkan bahwa secara keseluruhan, data yang digunakan pada masing-masing variabel dalam model penelitian ini stasioner.

\section{Uji Kointegrasi}

Pengujian Kointegrasi ini bertujuan untuk melihat apakah terdapat hubungan dalam jangka panjang atau pendek pada model VAR. Tabel 4.2 menunjukkan bahwa terdapat hubungan saling kointegrasi pada model penelitian yang ditunjukkan dengan nilai probabilitas lebih kecil dari alpha (5\%) yakni 0,000 dan nilai kritis lebih kecil dari nilai trace statistik yaotu 95,75366 lebih kecil dari 168,1902.

Tabel 4.2 Hasil Uji kointegrasi

\begin{tabular}{cccc}
\hline $\begin{array}{c}\text { Trace } \\
\text { Statistic }\end{array}$ & $\begin{array}{c}\text { Critical } \\
\text { Value }\end{array}$ & Probabilitas & Keterangan \\
\hline 168.1902 & 95.75366 & $0,0000^{* *}$ & $\begin{array}{c}\text { Terkointegra } \\
\text { si }\end{array}$ \\
\hline
\end{tabular}

Sumber: Lampiran C, data primer diolah. 2018

\section{Model VAR}

Hasil estimasi menunjukkan bahwa variabel GDP_Ind pada lag ke 1,2,3 memberikan pengaruh positif signifikan terhadap GDP Indonesia saat ini. Sementara itu, ketidakpastian Amerika Serikat pada lag ke 2 memberikan pengauh negatif signifikan terhadap GDP Indonesia yang ditunjukkan dengan koefisien negatif dan probabilitas sebesar 0,0930 lebih kecil 
dari alpa (10\%). Kondisi ini berarti bahwa ketika ketidakpastian Amerika Serikat meningkat, maka akan berdampak pada penurunan GDP Indonesia sebagai akibat dari shock ketidakpastian Amerika Serikat. Sementara itu, penurunan suku bunga Amerika Serikat tidak membawa dampak yang signifikann terhadap dinamika perekonomian di Indonesia. Hasil ini dikonfirmasi dengan nilai probabilitas lebih dari alpha (5\% dan $10 \%)$ sehingga suku bunga Amerika Serikat tidak membawa dampak signifikan bagi perekonomian Indonesia. Sementara itu, inflasi Amerika Serikat juga tidak berdampak signifikan terhadap perekonomian Indonesia. Kondisi tersebut dikonfirmasi dengan nilai probabilitas pada variabel CPI_US lebih besar dari nilai alpha (5\% dan 10\%). Dan untuk variabel domestik terkait dengan ekspor Indonesia juga tidak memberikan dampak yang cukup signifikna pada dinamika perekonomian Indonesia.

Tabel 4.3 Hasil Model VAR

\begin{tabular}{|c|c|c|c|c|}
\hline $\begin{array}{l}\text { GDP_In } \\
\mathrm{d}=\end{array}$ & $\begin{array}{l}1,8 \\
34 \\
+\end{array}$ & GDP_Ind(-1) & + GDP_Ind(-2) & + GDP_Ind (-3) \\
\hline & & {$[0,792]$} & {$[0,043]$} & {$[0,214]$} \\
\hline & & $(0,0000)$ & $(0,7838)$ & $(0,0190)$ \\
\hline & & -EPU_US(-1) & - EPU_US (-2) & -EPU_US (-3) \\
\hline & & {$[0,0004]$} & {$[0,0116]$} & {$[0,006]$} \\
\hline & & $(0,5091)$ & $(0,0930)$ & $(0,3235)$ \\
\hline & & -GDP_US (-1) & + GDP_US (-2) & -GDP_US (-3) \\
\hline & & {$[0,1216]$} & {$[0,6254]$} & {$[0,559]$} \\
\hline & & $(0,6647)$ & $(0,1100)$ & $(0,0544)$ \\
\hline & & -IR_US (-1) & + IR_US (-2) & -IR_US (-3) \\
\hline & & {$[0,3578]$} & {$[0,6714]$} & {$[0,4266]$} \\
\hline & & $(0,5905)$ & $(0,5484)$ & $(0,5644)$ \\
\hline & & + Exp_Ind (-1) & $+\operatorname{Exp} \_$Ind $(-2)$ & -Exp_Ind (-3) \\
\hline & & {$[2,3809]$} & {$[2,0109]$} & {$[2,8609]$} \\
\hline & & $(0,6255)$ & $(0,7315)$ & $(0,5225)$ \\
\hline & & +CPI_US (-1) & -CPI_US (-2) & + CPI_US (-3) \\
\hline & & {$[0,2207]$} & {$[0,0768]$} & {$[0,1341]$} \\
\hline & & $(0,5339)$ & $(0,7849)$ & $(0,7138)$ \\
\hline
\end{tabular}

\section{Impulse Response Fuction}

Hasil uji IRF bertujuan untuk melihat respon GDP Indonesia sebagai proksi dari dinamika perekonomian Indonesia terhadap variabel-variabel eksternal Amerika Serikat. Hasil Analisis IRF terlihat pada Gambar 4.4 sebagai berikut:
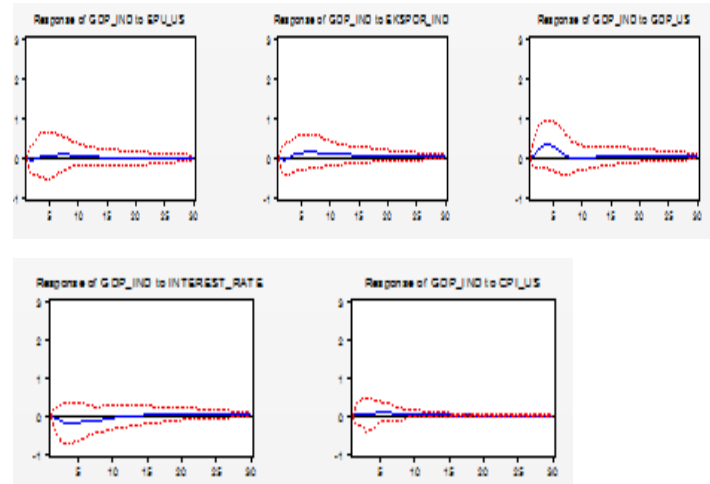

Hasil analisis menunjukkan bahwa GDP Indonesia memberikan respon yang berbeda dari shock yang ditunjukkan oleh masing-masing variabel. GDP Indonesia merespon stabil pada shock yang terjadi akibat dinamika ketidakpastian AS pada periode 15, namun di awal periode penelitian dari periode awal hingga periode 14 GDP Indonesia cukup memberikan respon yang bergejolak. Hal ini dilatarbelakangi pada awal penelitian tahun 1998 terjadi krisis sub prime mortgage yang mengakibatkan kelesuan perekonomian global juga didukung oleh ketidakpastian yang tinggi terutama di AS sebagai negara penggerak ekonomi dunia. Hal yang hampir serupa ditunjukkan oleh respon GDP Indonesia terhadap kinerja ekspor Indonesia sendiri dimana pada awal periode penelitian, GDP cukup merespon tinggi pergerakan ekspor Indonesia, sementara pada periode 8 hingga akhir periode penelitian cukup memberikan respon yang stabil. Respon yang cukup besar ditunjukkan oleh GDp Indonesia akibat adanya shock pada GDP AS pada wal periode yang menunjukkan respon positif dengan nilai tertinggi 0,3 pada periode ke 5 dan kemudian menunjukkan kestabilan kembali hingga akhir periode.

Sementara itu, respon GDP Indonesia cukup stabil dari awal periode hingga akhir periode dari shock yang terjadi pada dinamika suku bunga AS dan inflasi AS. Kondisi ini menyimpulkan bahwa, ketidakpastian Amerika Serikat dan GDP AS mampu direspon sensitif oleh dinamika perekomian Indonesia. Sehingga dapat dimaknai bahwa kebijakan AS terlebih pada kondisi ketidakpastian dan GDP AS memberikan sinyal besar pada dinamika perekonomian Indonesia yang ditunjukkan dengan respon yang cukup tinggi.

\section{Pembahasan}

Dari rangkaian hasil analisis secara keseluruhan dapat dikatakan bahwa penelitian ini berhasil memberikan sintesis atau bukti bahwa pada kenyataannya GDP US, Indeks Ketidakpastian Ekonomi US, suku bunga 3 bulanan US berpengaruh signifikan terhadap dinamika perekonomian Indonesia yang direpresentasikan oleh variabel berupa GDP Indonesia. Hasil analisis ini antara lain sejalan dengan penelitian yang telah dilakukan oleh Popp \& Zhang (2016) yang menyatakan bahwa Indeks Kepastian Ekonomi merupakan suatu indikator penting yang mempengaruhi adanya pergerakan atau dinamika pada suatu perekonomian. Ketidakpastian merupakan faktor yang dalam perkembangannya sampai saat ini terutama dalam ranah ekonomi menjadi hal yang tidak terduga pergerakannya serta sangat mempengaruhi stabil atau tidaknya kondisi perekonomian pada suatu negara. Terkait penelitian ini yaitu menggunakan Indeks Ketidakpastian Ekonomi US karena US pada dasarnya merupakan negara adidaya ataupun negara maju yang secara umum telah disepakati bersama oleh semua negara bahwa dinamika yang terjadi dalam perekonomian US pasti akan berpengaruh terhadap perekonomian negara lainnya di dunia. Fakta tersebut antara lain misalnya didukung oleh ketidakpastian pergerakan dolar US yang selalu dipantau oleh sebagian besar negara lainnya dan juga kenaikan suku bunga 3 bulanan US yang juga tidak terlepas dari perhatian para pembuat kebijakan negara lainnya. Selain itu, besarnya perekonomian US yang direpresentasikan oleh GDP US juga berpengaruh antara lain terhadap kegiatan ekspor impor dengan negara lainnya yang pada akhirya akan 
berdampak pada kondisi ekonomi negara lainnya. Sinyasinyal seperti itulah yang menjadikan mengapa negara US menjadi pusat perhatian oleh negara lainnya dan juga merupakan salah satu alasan fundamental yang menjadi dasar penulis untuk menggunakan indikator variabel negara US untuk menentukan faktor-faktor apa saja yang mempengaruhi dinamika perekonomian Indonesia.

Berdasarkan hasil analisis empiris yang telah dilakukan maka semakin memberikan bukti atau dukungan yang kuat bahwa inidkator-indikator ekonomi negara US terutama GDP US, suku bunga 3 bulanan US, dan Indeks Ketidakpastian Ekonomi US memiliki pengaruh yang signifikan terhadap perekonomian Indonesia. Hasil analisis ini memberikan gambaran bahwa perekonomian Indonesia turut dipengaruhi oleh ketiga indikator ekonomi negara US dengan proporsi yang cukup besar. Dari hasil tersebut maka pemerintah Indonesia khususnya para pembuat kebijakan harus lebih pruden atau lebih berhati-berhati dalam menentukan strategi kebijakannya. Disini para pembuat kebijakan terlebih dahulu harus cermat dan teliti dalam melakukan pemantauan terhadap indikator-indikator ekonomi negara US tersebut terutama dalam mengamati Indeks Ketidakpastian Ekonomi US sebab diantara ketiga indikator tersebut yang paling berfluktiatif pergerakannya adalah Indeks Ketidakpastian Ekonomi US. Sesuai dengan teori ekonomi yang telah ada yaitu dikatakan bahwa Kepastian Ekonomi merupakan suatu hal yang relatif sulit untuk diprediksi walaupun dalam perkembangannya saat ini telah ada indeks untuk mengukurnya yaitu berupa Indeks Ketidakpastian Ekonomi US. Oleh karena itu perlu pengamatan yang lebih berhati-hati dalam mengamati Indek Ketidakpastian Ekonomi US agar nantinya kebijakan yang dilakukan terkait ini dapat berjalan sesuai dengan tujuan yang diharapkan oleh pemerintah.

Sebagai negara yang dipengaruhi oleh perekonomian negara US, Indonesia harus dapat menyesuaikan dinamika atau perubahan yang terjadi terutama dalam bidang ekonomi agar tidak terjadi distorsi yang cukup besar sehingga perekonomian Indonesia dapat diusahakan senantiasa stabil dan agar tidak sampai terjadi krisis yang parah seperti krisis ekonomi tahun 1998 serta krisis ekonomi global tahun 2008. Pemerintah Indonesia harus mampu meminimalisir atau bahkan menghindari adanya suatu guncangan yang besar yang dapat membahayakan perekonomian Indonesia dengan jalan memberikan langkah preventif berupa langkah-langkah yang semakin pruden atu semakin berhati-hati dalam mengamati indikator-indikator ekonomi US sebelum pada akhirnya nanti melakukan suatu pengambilan keputusan.

\section{Simpulan}

\section{Simpulan}

Pengujian empiris tentang pengaruh ketidakpastian kebijakan ekonomi Amerika Serikat terhadap dinamika perekonomian Indonesia memeberikan pandangan mengenai pengaruh eksternal dari negara lain. Hal ini juga berarti bahwa dalam pelaksanaanya suatu negara selain dipengaruhi oleh factor internal negaranya sendiri juga dipengaruhi oleh factor eksternal dari negara lain. Hasil Pengujian empiris tentang pengaruh ketidakpastian kebijakan ekonomi Amerika Serikat terhadap dinamika perekonomian Indonesia menggunakan metode OLS menyatakan bahwa terdapat hubungan yang positf antar variabel dalam penelitian. Masing-masing variabel EPU, GDP US, dan suku bunga acuan US memberikan pengaruh signifikan terhadap dinamika GDP di Indonesia. Hasil ini didukung dengan nilai probabilitas statistik yang kurang dari 5\%. Temuan empiris ini sekaligus memberikan perluanya kajian terkait kebijakan yang diakibatkan oleh kondisi eksternal.

\section{Saran}

Berdasarkan pengujian empiris tentang pengaruh ketidakpastian kebijakan ekonomi Amerika Serikat terhadap dinamika perekonomian Indonesia yang diketahui bahwa bahwa terdapat hubungan yang positf antar variabel dalam penelitian. Dimana masing-masing variabel EPU, GDP US, dan suku bunga acuan US memberikan pengaruh signifikan terhadap dinamika GDP di Indonesia. Kondisi ini memberikan penekanan pada pentingnya penguatan dalam pengambilan kebijakan dalam merespon gejolak ketidakpastian perekonomian luar negeri.

Bagi penelitian selanjutnya pengujian empiris tentang pengaruh ketidakpastian kebijakan ekonomi Amerika Serikat terhadap dinamika perekonomian Indonesia adalah terkait dengan metode penelitian yang digunakan, diharapkan menggunakan metode yang lebih akurat dalam menggambarkan pengaruh kondisi ketidakpastian kebijakan luar negeri terhadap perekonomian Indonesia. Sementara itu penggunaan variabel terkait lainnya diharapkan mampu memberikan hasil yang beragam terkait hubungan ketidakpastian kebijakan luar negeri terhadap perekonomian domestik.

\section{Referensi}

Bernal, O., Gnabo, J. Y., \& Guilmin, G. (2016). Economic Policy Uncertainty and Risk Spillovers In The Eurozone. Journal of International Money and Finance, 65, 24-45. https://doi.org/10.1016/j.jimonfin.2016.02.017

Dahlhaus, T., \& Vasishtha, G. (2014). The Impact of U.S. Monetary Policy Normalization on Capital Flows to Emerging-Market Economies. In Bank of Canada.

Mwase, N., N'Diaye, P., Oura, H., Ricka, F., Svirydzenka, K., \& Zhang, Y. (2016). Spillover Notes, Issue 5: Spillovers from China: Financial Channels.

Popp, A., \& Zhang, F. (2016). The Macroeconomic Effects of Uncertainty Shocks: The Role of The Financial Channel. Journal of Economic $\begin{array}{lll}\text { Dynamics Control, and } & \end{array}$ https://doi.org/10.1016/j.jedc.2016.05.021

Samake, I., \& Yang, Y. (2014). Low-income Countries' Linkages to BRICS: Are There Growth Spillovers? Journal of Asian Economics, 30, 1-14. https://doi.org/10.1016/j.asieco.2013.09.002

Wang, C. L. (2007). Guanxi vs. Relationship Marketing: Exploring Underlying Differences. Industrial Marketing Management, 36(1), 81-86. https://doi.org/10.1016/j.indmarman.2005.08.002

Warjiyo, P. (2013). Indonesia : Global Spillover and Policy Response. 